\title{
Solvent-mediated extraction of fatty acids in bilayer oil paint models: a comparative analysis of solvent application methods
}

\author{
Lambert Baij ${ }^{1,2^{*}} \mathbb{D}$, Alina Astefanei ${ }^{1}$, Joen Hermans ${ }^{1,2}$, Francine Brinkhuis ${ }^{1}$, Heleen Groenewegen ${ }^{1}$, \\ Louise Chassouant ${ }^{1}$, Sofia Johansson ${ }^{1}$, Garry Corthals ${ }^{1}$, Caroline Tokarski ${ }^{3}$, Piet ledema ${ }^{1}$ and Katrien Keune ${ }^{1,2}$
}

\begin{abstract}
The impact of solvent exposure on oil paintings and the differences between solvent application methods are longstanding topics in cleaning studies. Solvent exposure is ideally kept to a minimum, because solvent swelling can lead to the extraction and displacement of reactive paint components. In particular, important concerns are fatty acids displacement resulting in metal soap formation and embrittlement of paint due to solvent exposure. In this study, the extraction of a saturated fatty acid (SFA) marker and the formation of zinc soaps were monitored to measure the impact of solvent cleaning on tailored bilayer model systems for aged oil paint. Three methods of solvent application were compared: cotton swab, rigid gel and Evolon tissue (with different solvent loading). The samples were analysed by surface acoustic wave nebulization mass spectrometry (SAWN-MS) and thermally-assisted hydrolysis and methylation pyrolysis gas chromatography mass spectrometry (THM-Py-GC/MS) by comparing the calculated margaric:palmitic acid $\left(C_{17}: C_{16}\right)$ ratio determined in the extracts (taken from the swab, gel or Evolon tissue). We conclude that both swab cleaning and squeezed Evolon tissue application result in comparable SFA extraction. The rigid gel and Evolon with controlled solvent-loading limit the amount of SFA extraction. The distribution of $C_{17}$ after solvent application was visualised using static Time-of-Flight Secondary lon Mass Spectrometry (ToF-SIMS) on cross sections, showing that $C_{17}$ redistribution took place in all cases where solvent was applied. Crystalline zinc soaps formation was not observed after 5 min of ethanol exposure in the embedded cross-sections with imaging ATR-FTIR, indicating that solvent exposure does not immediately trigger the formation of crystalline metal soaps. However, significant zinc soap formation was found after 30 min of ethanol exposure using Evolon tissue without controlled loading. This study contributes to a better understanding of the impact of different methods of solvent application on oil paintings and highlights important differences between these methods.
\end{abstract}

Keywords: Oil paint cleaning, Fatty acid marker, Zinc soap

\section{Introduction}

Scientific research focusing on the cleaning of oil paintings has evolved greatly since the early investigations in the 1950s [1, 2]. As stated by Phenix and Sutherland [3], the role of these scientific investigations is 'to inform, guide and improve the art and craft of cleaning practice.' However, scientific cleaning studies face many challenges [3-6]

\footnotetext{
*Correspondence: c.l.m.baij@uva.nl

${ }^{1}$ Van 't Hoff Institute for Molecular Science, University of Amsterdam, Science Park 904, PO box 94157, 1090GD Amsterdam, The Netherlands Full list of author information is available at the end of the article
}

such as making a fair compromise between the reproducibility of the cleaning experiment and the practical applicability of the simulated treatment procedure.

We have previously shown that linseed-oil based model systems can provide important insights about solvent action on oil paints. For example, we studied the reaction of amorphous metal carboxylates with externally provided saturated fatty acids (SFAs) to form metal soaps (crystalline complexes of metal ions and long chain saturated fatty acids ${ }^{1}$ ) in both pigmented and unpigmented

${ }^{1}$ This definition is used in the current paper. 
(ionomer) model paints [7]. In that study, a reservoir containing SFAs dissolved in acetone was used to deliver the SFAs to the model paints. It was concluded that the exposure of amorphous metal carboxylates to SFAs in solution is a sufficient condition for metal soap formation. In addition, the transport rate of SFAs was found to be strongly enhanced by solvent swelling and traces of water [7]. The diffusion of neat solvents [8] or solvents confined in rigid gels [9] into linseed-oil based ionomers was also studied. It was shown that the rate of solvent diffusion is correlated to the swelling capacity and varies considerably between different solvents. The diffusion of organic solvents and water into linseed oil based ionomers was found to be of similar magnitude for both free solvents and solvents released by gels, indicating that the solvent uptake by non-porous linseed oil based ionomers is relatively slow compared to the rate of solvent release by the gels [9].

The amount of solvent delivered to the paint surface is strongly determined by the cleaning method applied. In this study, three different cleaning methods are systematically compared to measure the impact of solvent cleaning methods on the internal chemistry of a multi-layer paint system. The three different cleaning methods are:

- The cotton swab, traditionally widely used for varnish removal

- Evolon ${ }^{\circledR}$ CR tissue, an alternative used for varnish removal and composed of a Nylon/polyethylene terephthalate fabric [10]

- Nanorestore ${ }^{\circledR}$ Max Dry rigid gel, can be used for varnish or surface dirt removal and composed of semi-interpenetrating polyhydroxyethylmethacrylate (pHEMA) and polyvinylpyrrolidone (PVP) networks [11].

Two criteria of cleaning impact are used: (1) the amount of extracted free SFAs and (2) to what extent zinc soap formation is triggered by the simulated cleaning action. Ethanol was chosen for the comparison of solvent application methods because it is commonly used for the removal of aged varnishes. Zinc soap crystallisation was chosen because it is a widespread oil paint degradation phenomenon that can be enhanced by solvent swelling.

For the systematic study of SFA extraction and zinc soap formation, we designed a bilayer model system that allows for both tracking a specific free SFA marker between different layers, as well as following the crystallisation of zinc soaps. The bottom layer consists of polymerised linseed oil with an added margaric acid $\left(\mathrm{C}_{17}\right)$ marker $\left(\mathrm{pLOC}_{17}\right)$ and serves as a source of SFAs with a realistic (5 wt.\%) free SFAs concentration. The top layer consists of a reactive zinc ionomer layer (Znpol), which

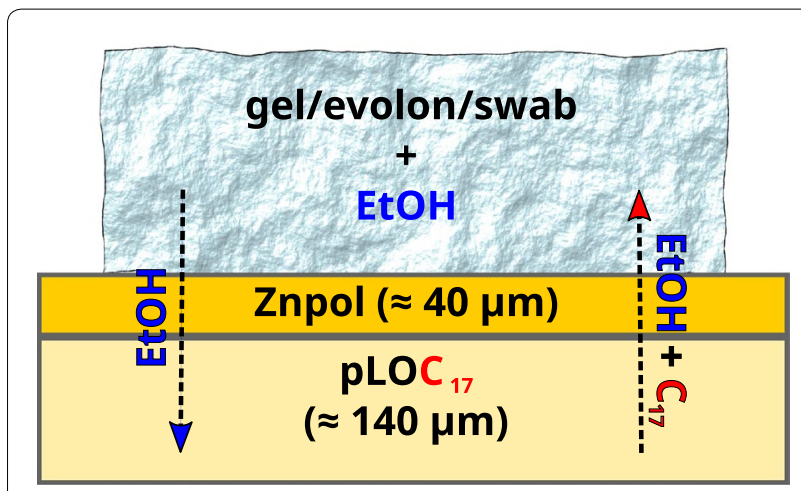

Fig. 1 Overview of $\mathrm{pLOC}_{17}-$ Znpol bilayer model systems. Solvent is applied from the top and swells the system briefly. $C_{17}$ is extracted from bottom to top upon solvent swelling. After solvent exposure the $\mathrm{C}_{17}: \mathrm{C}_{16}$ ratio in the gel/evolon/swab sample is determined using MS

contains amorphous zinc carboxylates that can react with SFAs from the bottom layer and form zinc soaps [7, 12]. These bilayer model systems (denoted $\mathrm{pLOC}_{17}-\mathrm{Znpol}$, see Fig. 1) contain both SFAs and zinc carboxylates in different layers, but only form zinc soaps upon solvent exposure. The $\mathrm{pLOC}_{17}-\mathrm{Znpol}$ model mimics the molecular structure and reactivity of an aged binding medium in a bilayer paint system. In fact, the model represents any multilayer system where a difference in free SFA concentration between paint layers exists and migration across layers can induce metal soap formation.

To perform relative quantification of the extraction of $\mathrm{C}_{17}$, palmitic acid $\left(\mathrm{C}_{16}\right)$, naturally present in linseed oil, is used as an internal standard. $\mathrm{C}_{17}$ is a SFA containing 17 carbon atoms that does not naturally occur in linseed oil and can therefore be used as a marker. Because the $\mathrm{pLOC}_{17}-\mathrm{Znpol}$ model systems are consistently made with the same linseed oil (LO) and subsequently aged and stored under identical conditions, all model paint samples are assumed to contain identical $\mathrm{C}_{16}$ concentrations. The diffusion rate of $\mathrm{C}_{17}$ and $\mathrm{C}_{16}$ across the layers is assumed to be of similar magnitude due to their comparable aliphatic chain length. Consequently, the $C_{17}: C_{16}$ ratio (determined in the extract) can be used for relative quantification of the $\mathrm{C}_{17}$ extraction from the lower layer, in relation to that from the paint system overall. In this paper, the $\mathrm{C}_{17}: \mathrm{C}_{16}$ ratio is used as a measure of the $\mathrm{C}_{17}$ transport between the layers. Using the $\mathrm{C}_{17}: \mathrm{C}_{16}$ ratio also corrects for deviations in the surface area that was cleaned or variations in the size of Evolon/gel/swab tissue.

Surface acoustic wave nebulization mass spectrometry (SAWN-MS) [13] and thermally-assisted hydrolysis and methylation pyrolysis gas chromatography mass spectrometry (THM-Py-GC/MS) [14] are used for relative quantification of the extracted free SFAs. SAWN-MS 
allows rapid analysis without derivatization and is a soft ionisation technique [13]. THM-Py-GC/MS is a common method for the analysis of paint extracts and is included for comparison. To visualise the migration of SFAs after solvent application, static Time-of-Flight Secondary Ion Mass Spectrometry (ToF-SIMS) is measured on crosssections. Possible formation of crystalline zinc soaps is investigated using imaging ATR-FTIR on cross-sections.

This work combines model systems of known composition with practically relevant solvent application methods. By comparing different cleaning methods, these experiments can contribute to a better understanding of the impact of solvent action on oil paints and support the development of improved conservation and restoration strategies.

\section{Experimental}

\section{Sample preparation}

Zinc sorbate complexes were synthesised according to previously published procedures [8]. Binding medium model systems Znpol were made by grinding $100 \mathrm{mg}$ zinc sorbate with $900 \mathrm{mg}$ cold-pressed untreated linseed oil (LO, Kremer Pigmente) to a smooth paste with mortar and pestle. The concentration of metal ions in the uncured sample mixture was equivalent to a molar metal carboxylate bond to triacylglyceride (TAG) ester ratio (COOM/COOR) of 0.23 . This concentration corresponds to roughly $333 \mathrm{mM}$ zinc in the polymer. The mixture was applied to $50 \times 75 \mathrm{~mm}$ glass slides and spread with a draw-down bar to achieve a wet thickness of $90 \mu \mathrm{m}$. The layers were cured for $17 \mathrm{~h}$ in an air-circulated oven at $150^{\circ} \mathrm{C}$, resulting in transparent homogeneous yellow films with a thickness of around $40 \mu \mathrm{m}$. Films of polymerised linseed oil with margaric acid marker $\mathrm{pLOC}_{17}$ were prepared in a similar fashion using $5 \mathrm{wt} . \%$ of margaric acid in linseed oil, a wet thickness of $190 \mu \mathrm{m}$ and cured for $5 \mathrm{~h}$ at $150^{\circ} \mathrm{C}$. The thickness of each sample was measured with a digital micrometer accurate to $1 \mu \mathrm{m}$.

\section{Cross-section preparation}

Cross-sections of bilayer model systems were embedded in Technovit ${ }^{\circledR} 2000$ LC resin and cured in a Technovit ${ }^{\circledR}$ 2000 LC Technotray POWER-Light Polymerization Unit for $30 \mathrm{~min}$. The cross-section was sanded down using a MOPAS XS Polisher and wet and dry (Micromesh) polishing techniques. For ToF-SIMS mapping, cross-sections were used without gold coating.

\section{Simulated cleaning test procedure}

Nanorestore ${ }^{\circledR}$ Max Dry was used as received from CSGI (http://www.csgi.unifi.it). Gels were kept in a sealed container loaded with ethanol for at least $12 \mathrm{~h}$ before use and dried with paper tissue before application. Evolon ${ }^{\circledR} \mathrm{CR}$ tissue (http://www.deffner-johann.de/evolonr-cr.html) was cut into $1 \times 1 \mathrm{~cm}$ squares, washed with acetone and ethanol using a Buchner funnel, dried and subsequently soaked with ethanol. Before use the samples were squeezed using nitrile gloves and left to evaporate for 1 min (samples denoted Evolon-sq.). The Evolon samples with controlled loading were kept overnight in a sealed container loaded with ethanol. Strips of $2 \times 5 \mathrm{~cm}$ were loaded with 34\% ethanol (87.4 mg Evolon/102.7 mg ethanol) or 51\% (92.3 mg Evolon / $149.1 \mathrm{mg}$ ethanol) before use. During solvent application, Evolon and gel samples were covered with a Melinex film to avoid solvent evaporation from the top. A thin glass slide was placed on top of the Melinex film to maintain a constant pressure across all samples. Hand-rolled cotton swabs were used and swabbing was carried out continuously (without rewetting the swab) for $5 \mathrm{~min}$ with very gentle pressure. Swab cleaning was always carried out by the same person. All simulated cleaning tests were executed in triplicate.

\section{THM-Py-GC/MS analysis}

Samples were analysed by THM-Py-GC/MS [14]. Tetramethylammonium hydroxide (TMAH) was added to the samples prior to analysis to convert labile compounds to more volatile products. For background subtraction, GC-MS runs with a blank sample (5\% methanolic solution of TMAH with internal tridecanoic acid $\left(\mathrm{C}_{13}\right)$ standard) were performed before analysis and subtracted for each sample.

A Frontier Lab PY-2020D double-shot pyrolyzer system was used, with the interface maintained at $320^{\circ} \mathrm{C}$. The pyrolyzer was attached to an Agilent Technologies 5975C inert MSD/7890A gas chromatography/mass spectrometer. The split injector was set to $290^{\circ} \mathrm{C}$ with a split ratio of 20:1 and no solvent delay. An Agilent J\&W Ultra-inert DB-5MS capillary column was used for the separation $(20 \mathrm{~m} \times 0.18 \mathrm{~mm} \times 0.18 \mu \mathrm{m})$. Helium carrier gas was set to $0.9 \mathrm{ml} / \mathrm{min}$. The $\mathrm{GC}$ oven temperature program was: $35^{\circ} \mathrm{C}$ for $1.5 \mathrm{~min} ; 60^{\circ} \mathrm{C} / \mathrm{min}$ to $100^{\circ} \mathrm{C} ; 14^{\circ} \mathrm{C} / \mathrm{min}$ to $250^{\circ} \mathrm{C} ; 6^{\circ} \mathrm{C} / \mathrm{min}$ to $315^{\circ} \mathrm{C}$; 1.5 -min isothermal. The MS transfer line was at $250^{\circ} \mathrm{C}$, the source at $220^{\circ} \mathrm{C}$ and the MS quad at $150^{\circ} \mathrm{C}$. The mass spectrometer was scanned from 30 to $600 \mathrm{~m} / \mathrm{z}$.

Evolon samples were cut into $4 \times 3 \mathrm{~mm}$ squares and placed in a glass vial, $30 \mu \mathrm{l}$ of a $25 \%$ methanolic solution of TMAH was added for derivatization. Gel and Swab samples were first immersed overnight in $0.5 \mathrm{ml}$ ethanol, subsequently the ethanol was evaporated using a $\mathrm{N}_{2}$ flow before $30 \mu \mathrm{l}$ of TMAH solution was added. Samples were pyrolyzed using a Frontier Direct EGA method: $360^{\circ} \mathrm{C}$ initial furnace temperature; $500^{\circ} \mathrm{C} / \mathrm{min}$ to $700^{\circ} \mathrm{C}$; 0.3 min isothermal. 


\section{SAWN-MS analysis}

Experiments were conducted with a TripleToF 5600+ mass spectrometer (AB SCIEX, Concord, ON, Canada) and a SAWN device from Deurion (Seattle, WA, USA). The setup is described in more detail elsewhere [13]. For each MS analysis, SAWN was regulated by application of power to the electrodes (approximately $5 \mathrm{~W}$ ) in continuous mode. Approximately $10 \times 1 \mu \mathrm{l}$ of sample in EtOH was loaded on the chip while the data was accumulated in a single data file. Data was acquired with an interface heater temperature of $150^{\circ} \mathrm{C}$, the inlet and outlet gas pressures were set at $0 \mathrm{psi}$, and the curtain gas pressure was set to the minimum valued allowed, $10 \mathrm{psi}$. The mass spectra were acquired $(50-500 \mathrm{~m} / \mathrm{z})$ in negative ionisation mode for $60 \mathrm{~s}$ using multichannel acquisition with an accumulation time of $3 \mathrm{~s}$.

Evolon gel and swab samples were transferred to an Eppendorf tube and $200 \mu \mathrm{l}$ of ethanol was added. A small piece of cotton swab samples was cut and transferred to a different tube where and additional $50 \mu \mathrm{l}$ ethanol was added. All samples were vortexed for $2 \mathrm{~min}$ before analysis.

\section{ToF-SIMS imaging}

The ToF-SIMS analyses were carried out in negative mode using a ToF-SIMS 5 (ION-ToF GmbH Germany) instrument equipped with a $\mathrm{Bi}^{+}$liquid metal ion gun (LMIG). The samples were bombarded with a pulsed $\mathrm{Bi}_{3}^{+}$primary ion beam $(25 \mathrm{KeV}, 0.25 \mathrm{pA})$ rastered over a $250 \times 250 \mu \mathrm{m}^{2}$ surface area. With 100 scans and $256 \times 256$ pixels, the total primary ion dose did not exceed $10^{12}$ ions $/ \mathrm{cm}^{2}$ ensuring static conditions. Charge effects due to primary ion beam were compensated by means of a $20 \mathrm{eV}$ pulsed electron flood gun. Cycle time was fixed at $100 \mu$ s so that it was possible to detect secondary molecular ions up to $800 \mathrm{~m} / z$. Etching of 5 min with $\mathrm{Cs}^{+} 2 \mathrm{kV}(100 \mathrm{nA})$ rastered over an area of $800 \times 800 \mu \mathrm{m}^{2}$ were performed before spectra acquisition in order to remove any surface contamination.

\section{ATR-FTIR and imaging ATR-FTIR}

Cross-sections were analysed with imaging-ATR-FTIR using a Perkin Elmer Spotlight 400 FTIR microscope equipped with a $16 \times 1$ pixel linear MCT array detector at $8 \mathrm{~cm}^{-1}$ resolution and a Perkin Elmer ATR Ge crystal accessory. Spectra were collected in the $750-4000 \mathrm{~cm}^{-1}$ range using an pixel size of $1.56 \mu \mathrm{m}$ (diffraction limited spatial resolution), an interferometer speed of $2.2 \mathrm{~cm} / \mathrm{s}$ and averaging over 2 scans. Raw imaging ATR-FTIR data was processed using a custom Matlab script.

\section{Results and discussion}

Mass spectrometric analysis of extracts

SAWN-MS and THM-Py-GC/MS in negative ionisation mode were used to determine the $\mathrm{C}_{17}: \mathrm{C}_{16}$ ratio in ethanolic extracts from the cotton swab, the Evolon tissue (with different loading) and the rigid gel. The $\mathrm{C}_{17}: \mathrm{C}_{16}$ ratio can be taken as a measure of the extraction capacity of the cleaning method used. The results obtained after 5 min of ethanol exposure are summarised in Table 1. An ethanol exposure time of $5 \mathrm{~min}$ was chosen because this is within the range of typical exposure times used in paintings restoration practice. An example of a typical SAWN-MS spectrum (for Evolonsq) is shown in Fig. 2.

It is clear from Table 1 that the amount of $\mathrm{C}_{17}$ extraction varies considerably between different methods of solvent application and between different ethanol loading for Evolon. The $\mathrm{C}_{17}$ extraction was greatest using the cotton swab $(4.6 \pm 1.5)$, followed by Evolon without controlled solvent loading (Evolon-sq., $3.2 \pm 0.6$ ). Even though simulated treatments were executed by one person, the standard deviation for the cotton swab was also largest, showing this method is poorly reproducible. The $\mathrm{C}_{17}$ extraction for the Max Dry gel $(1.7 \pm 0.3)$ was much lower than for the swab and for Evolon-sq and can not be altered using a different amount of solvent. In contrast, controlled solvent loading of Evolon has a strong effect on the amount of $\mathrm{C}_{17}$ extraction and brings the performance of Evolon on par with Max Dry gels. It is thus important to control the amount of solvent that is contained in Evolon. It was not possible to distinguish between Evolon-34\% and Evolon-51\% within the calculated error of the $C_{17}: C_{16}$ ratio. Since the SAWN-MS response within repeats of the same extract was small (relative standard deviation $<10 \%$, determined from triplicates), this was probably due to variations in the model systems and extraction methods.

\begin{tabular}{|c|c|}
\hline Sample & $\begin{array}{l}\text { Ratio } \\
\mathrm{C}_{17}: \mathrm{C}_{16}\left(\times 10^{-2}\right)\end{array}$ \\
\hline Evolon-sq. (5 min) & $3.2 \pm 0.6$ \\
\hline Evolon-34\% (5 min) & $1.8 \pm 0.4$ \\
\hline Evolon-51\% (5 min) & $1.5 \pm 0.2$ \\
\hline Max Dry gel (5 min) & $1.7 \pm 0.3$ \\
\hline Cotton swab (5 min) & $4.6 \pm 1.5$ \\
\hline
\end{tabular}

Values are an average of triplicate measurements, standard deviation indicated after \pm 


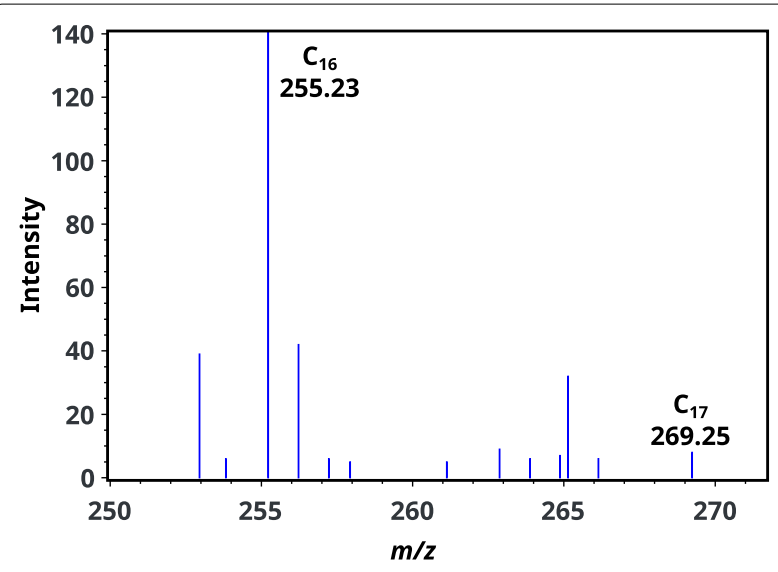

Fig. 2 An example of a typical SAWN-MS spectrum for the extract taken from Evolon-sq showing the range $250-275 \mathrm{~m} / \mathrm{z}$.
The possible influence of different solvent exposure times is a concern in paintings restoration. Figure 3 shows an overview of the $C_{17}: C_{16}$ peak integral ratios after different ethanol exposure times obtained using THM-Py-GC-MS [14]. Increasing the ethanol exposure time leads to an increase in the amount of $\mathrm{C}_{17}$ extracted for all methods of solvent application. In this set, Evolon without controlled solvent loading was used. We have excluded 10 and $30 \mathrm{~min}$ exposure for the cotton swab since this would involve an unrealistic amount of swabbing and the $40 \mu \mathrm{m}$ thin Znpol model systems were not resistant to prolonged mechanical action.

Although the absolute $\mathrm{C}_{17}: \mathrm{C}_{16}$ ratios obtained with THM-Py-GC/MS cannot be compared directly to SAWN-MS measurements due to the difference in ionisation methods, the THM-Py-GC/MS results confirm the trends in $\mathrm{C}_{17}$ extraction obtained with SAWN-MS after $5 \mathrm{~min}$ of ethanol exposure. It is noted that there is an order of magnitude difference between the $C_{17}: C_{16}$ ratios obtained by SAWN-MS and THM-Py-GC/MS. In order to explain this difference between SAWN-MS and THM-Py-GC/MS data, a detailed investigation is needed which lies outside the scope of this research.

SAWN-MS provides significant advantages over THMPy-GC/MS due to the reduced acquisition and sample preparation time, the lower fragmentation during ionisation and the ease of operation. The total time necessary for sample preparation and analysis was about $5 \mathrm{~min}$ per sample.

\section{ToF-SIMS images of $\mathrm{C}_{17}$ redistribution after cleaning}

ToF-SIMS mapping [15] was performed on cross-sections of $\mathrm{pLOC}_{17}-\mathrm{Znpol}$ model systems in order to visualise the $\mathrm{C}_{17}$ redistribution after ethanol exposure. Figure 4a shows the distribution of $\mathrm{C}_{17}(269.25 \mathrm{~m} / z)$ for

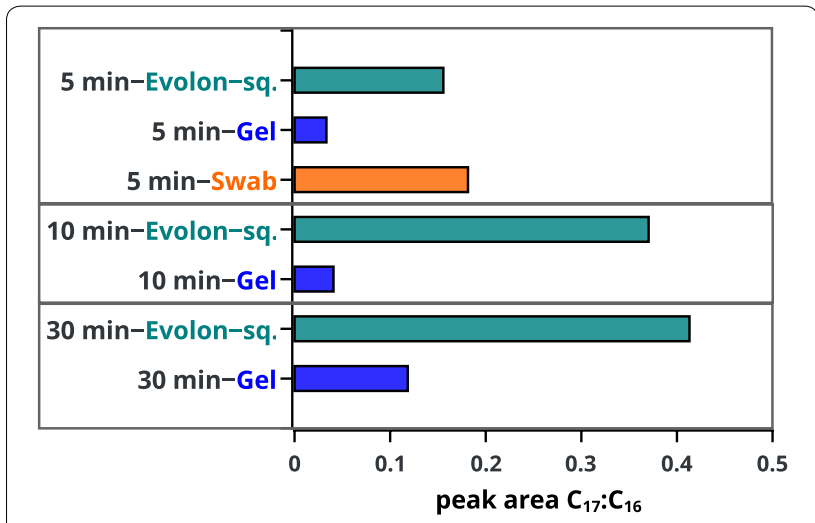

Fig. 3 Overview of the $C_{17}: C_{16}(284.27: 270.26 \mathrm{~m} / \mathrm{z})$ peak area ratios obtained from the total ion current $(\mathrm{TIC})$ chromatogram of THM-Py-GC/MS measurements on extracts taken from the Evolon tissue, the swab, and the gel with increasing exposure time

the blank, Evolon 34\%, swab and gel samples after 5 min of ethanol exposure (no ethanol exposure in the blank). The total signal intensities can vary between different samples and within layers due to surface topology variations inherent in cross-section preparation and analysis. As a result of these preparation and instrumental conditions during analysis, not all the ToF-SIMS images are displayed at the same scale. This set of ToF-SIMS images will be used for qualitative information on the distribution of $\mathrm{C}_{17}$ inside the Znpol layer only.

Based on the clear visibility of the $\mathrm{C}_{17}$ signal in the Znpol layer, Fig. 4a shows that significant $\mathrm{C}_{17}$ migration into the Znpol layer took place in all cases where solvent was applied. These results are in good agreement with MS analysis of the extracts. The images also suggests that swab rolling and gel cleaning cause a more homogeneous $\mathrm{C}_{17}$ redistribution across the $\mathrm{Znpol}$ layer compared to Evolon tissue, where $\mathrm{C}_{17}$ is more concentrated close to the $\mathrm{pLOC}_{17}$ layer.

\section{Imaging ATR-FTIR on cross sections after cleaning}

The same set of cross-sections used for ToF-SIMS was analysed with imaging ATR-FTIR spectroscopy [16] in order to check if $5 \mathrm{~min}$ of ethanol exposure and the effective $\mathrm{C}_{17}$ migration triggered the formation of zinc soaps. We previously showed that solvent swelling can enhance both the transport rate of SFAs and subsequent metal soap crystallisation [7].

Figure $4 \mathrm{~b}$ shows a selection of imaging ATR-FTIR spectra for all samples, normalised on the ester carbonyl (COOR) band at $1740 \mathrm{~cm}^{-1}$. The complete surface of $\mathrm{pLOC}_{17}-\mathrm{Znpol}$ system was imaged and the area of Znpol divided in 50 slabs (slices). A selection of three spectra (averages of slabs located at the top, middle and bottom of the cross-section) are shown and shifted for 


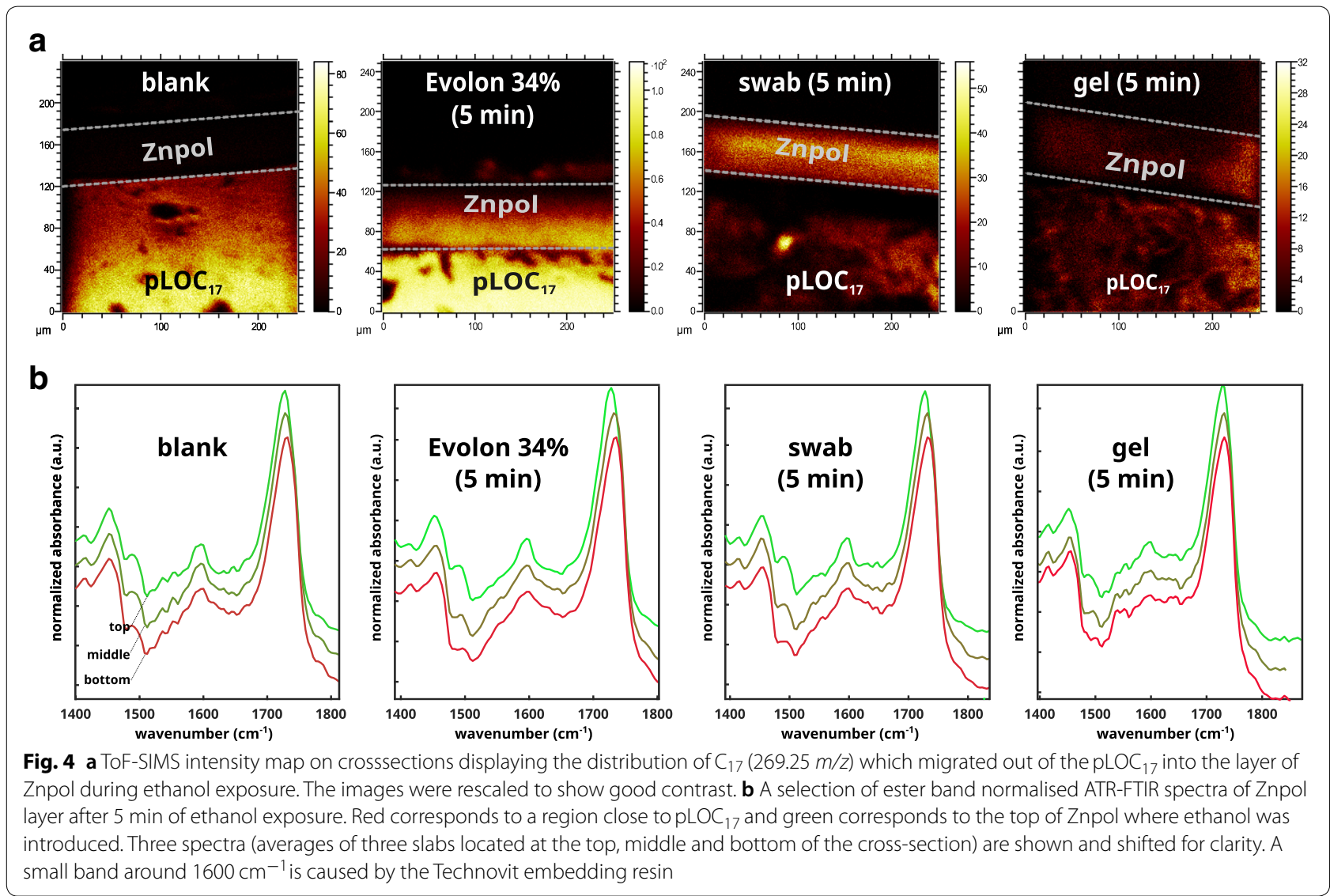

clarity. Each spectrum is an average of the FTIR spectra that make up one slab and is colour coded according to position: red is close to the $\mathrm{pLOC}_{17}$ layer, green is on the side where ethanol was introduced. The complete absence of a sharp IR absorption band at $1540 \mathrm{~cm}^{-1}$ (associated with crystalline zinc soaps) proves that $5 \mathrm{~min}$ of ethanol exposure does not lead to the formation of detectable amounts of zinc soaps in these samples. After 7 months, all samples (including the blank) showed zinc soap formation (see Additional file 1: Figure S1 for FTIR images recorded 7 months after cleaning).

Figure 3 showed that longer ethanol exposure results in increasing extraction of $\mathrm{C}_{17}$. It is therefore possible that longer solvent exposure times are required to trigger zinc soap formation in these model systems. Imaging ATR-FTIR spectra were taken from a cross-section of our model system exposed to ethanol for $30 \mathrm{~min}$ using Evolon-sq to investigate if an increased solvent exposure time would lead to the formation of zinc soaps. Figure 5a displays an ATR-FTIR map of the crystalline zinc soap $\left(1540 \mathrm{~cm}^{-1}\right)$ distribution in $\mathrm{pLOC}_{17}-\mathrm{Znpol}$ bilayer model systems after $30 \mathrm{~min}$ ethanol exposure. The lower part of the Znpol layer clearly shows the formation of crystalline zinc soaps, evidenced by a sharp
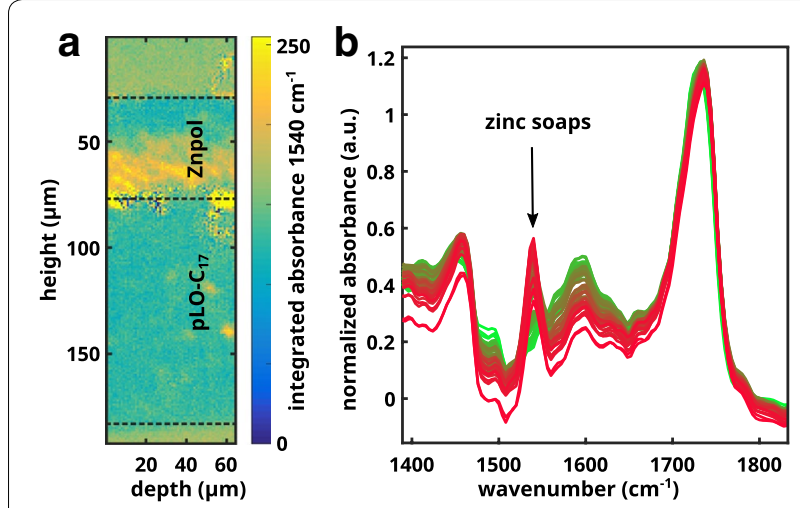

Fig. 5 a Imaging ATR-FTIR map showing the distribution of crystalline zinc soaps $\left(1540 \mathrm{~cm}^{-1}\right)$ in pLOC $_{17}-$ Znpol bilayer model systems after 30 min ethanol exposure using Evolon-sq and $\mathbf{b}$ corresponding colorcoded FTIR spectra. The layer was divided in 50 slabs and spectra were averaged over each slab, red corresponds to a region close to $\mathrm{pLOC}_{17}$, green corresponds to the top of Znpol where ethanol was introduced

peak at $1540 \mathrm{~cm}^{-1}$ in Fig. $5 \mathrm{~b}$. The fact that the zinc soaps are located near the interface (see also Additional file 1: Figure S2) with the $\mathrm{pLOC}_{17}$ layer, demonstrates that zinc 
soap formation is triggered by $\mathrm{C}_{17}$ SFAs sourced from that layer. Using imaging ATR-FTIR, we can conclude that zinc soap formation is clearly enhanced by prolonged solvent exposure.

\section{Conclusions}

Our results stress that the method of solvent application and the duration of solvent exposure can directly influence SFA migration and zinc soap formation in oil paint. Using smart model systems, we studied the impact of solvent cleaning using the relative amount of $\mathrm{C}_{17}$ extraction and zinc soap formation as indicators. SAWN-MS provided significant advantages over THMPy-GC/MS, featuring a reduced time for acquisition, analysis and sample preparation. Our results have practical implications for paintings restoration and showed that the amount of SFA extraction is significantly different between different methods of solvent application. Firstly, traditional cotton swab rolling extracts more SFAs compared to a rigid gel and an Evolon tissue (with controlled loading) and is less reproducible. Secondly, controlling the solvent loading of Evolon tissue reduces the amount of SFA extraction from underlying paint layers. Thirdly, reducing solvent application time as much as possible is crucial for limiting unwanted extraction of non-crosslinked components. Although ToF-SIMS mapping showed that $\mathrm{C}_{17}$ redistribution took place in all simulated cleaning tests after $5 \mathrm{~min}$, the migration of SFAs inside the zinc ionomer did not immediately lead to zinc soap formation. However, prolonged (30 min) solvent exposure using Evolon tissue without controlled loading did lead to the immediate formation of zinc soaps.

\section{Additional file}

Additional file 1. Imaging ATR-FTIR data showing the formation of zinc soaps over time and the formation of zinc soaps close to the $\mathrm{PLOC}_{17}$ layer.

\section{Abbreviations}

SFA: saturated fatty acid; LO: linseed oil; COOR: ester; COOM: metal carboxylate; Znpol: zinc ionomer; $\mathrm{pLOC}_{17}$ : polymerised LO with $5 \mathrm{wt} . \% \mathrm{C}_{17} ; \mathrm{C}_{13}$ : tridecanoic acid; $C_{16}$ : palmitic acid; $C_{17}$ : margaric acid; SAWN-MS: surface acoustic wave nebulization mass spectrometry; THM-Py-GC/MS: thermally-assisted hydrolysis and methylation pyrolysis gas chromatography mass spectrometry; ATR-FTIR: attenuated total reflection Fourier transform infrared spectroscopy; $\mathrm{PHEMA}$ : polyhydroxyethylmethacrylate; PVP: polyvinylpyrrolidone; TMAH: tetramethylammonium hydroxide.

\section{Acknowledgements}

The authors are grateful to Nicolas Nuns (N.N.) for the ToF-SIMS analysis, Selwin Hageraats for the development of Matlab spectral processing algorithms, and Gwen Tauber and Laura Raven for useful discussions.

\section{Authors' contributions}

$L B$ and $K K$ designed the experiments and interpreted the data. $L B, H G, F B, S J$ and LC prepared the samples. LB carried out (imaging)-ATR-FTIR and LB, KK, CT and NN ToF-SIMS measurements. KK, FB and HG carried out the THM-Py-GC/ $M S$ and A.A. the SAWN-MS analysis. LB wrote the manuscript. LB, AA, PDI, GC, $\mathrm{CT}$, JJH and KK edited the manuscript. KK supervised the project. All authors read and approved the final manuscript.

\section{Funding}

This research is carried out within the framework of the NANORESTART project funded by the European Union's Horizon 2020 research and innovation program under Agreement No. 646063.

\section{Availability of data and materials}

Imaging ATR-FTIR data showing the formation of zinc soaps over time and the formation of zinc soaps close to the pLOC $_{17}$ layer.

\section{Competing interests}

The authors declare that they have no competing interests.

\section{Author details}

${ }^{1}$ Van 't Hoff Institute for Molecular Science, University of Amsterdam, Science Park 904, PO box 94157, 1090GD Amsterdam, The Netherlands. ${ }^{2}$ Conservation and Science, Rijksmuseum Amsterdam, Museumstraat 1, PO box 74888 , 1070DN Amsterdam, The Netherlands. ${ }^{3}$ Institute of Chemistry and Biology of Membranes \& Nano-objects, Proteome Platform, University of Bordeaux, UMR CNRS 5248, 33000 Bordeaux, France.

Received: 4 February 2019 Accepted: 3 May 2019

Published online: 18 May 2019

\section{References}

1. Stolow N. The action of solvents on drying-oil films: parts i and ii. J Oil Colour Chem Assoc. 1957;40(5-6):377-402.

2. Browne FL. Swelling of paint films in water viii: swelling of linseed oil paints in water and organic liquids. For Prod J. 1956;6:312-8.

3. Phenix A, Sutherland K. The cleaning of paintings: effects of organic solvents on oil paint films. Stud Conserv. 2001;46(sup1):47-60. https://doi. org/10.1179/sic.2001.46.Supplement-1.47.

4. Michalski S. A physical model of the cleaning of oil paint. Stud Conserv. 1990;35(sup 1):85-92. https://doi.org/10.1179/sic.1990.35.s1.020.

5. Zumbühl S. Parametrization of the solvent action on modern artists' paint systems. Stud Conserv. 2014;59(1):24-37. https://doi.org/10.1179/20470 58413Y.0000000099.

6. Graczyk A, Phenix A. Mapping the nonideal: reflections on graphical representation of solubility parameters as a tool in conservation practice. AIC Paint Spec Group Postprint. 2015;28:89-97.

7. Baij L, Hermans JJ, Keune K, ledema P. Time-dependent ATR-FTIR spectroscopic studies on fatty acid diffusion and the formation of metal soaps in oil paint model systems. Angewandte Chemie Int Ed. 2018;57(25):7351-4. https://doi.org/10.1002/anie.201712751.

8. Baij L, Hermans JJ, Keune K, ledema PD. Time-dependent ATR-FTIR spectroscopic studies on solvent diffusion and film swelling in oil paint model systems. Macromolecules. 2018;51(18):7134-44. https://doi.org/10.1021/ acs.macromol.8b00890.

9. Baij L, Keune K, Hermans JJ, Noble P, ledema PD. Time-resolved ATR-FTIR studies on the release of solvents from cleaning gels into model systems of oil paint binding media. In: Ormsby B, Townsend JH, Wolbers R, editors. Gels in the conservation of art. London: Archetype Publications; 2017. p. $316-21$.

10. Vergeer $\mathrm{M}$, van den Berg KJ, van Oudheusden S, Stols-Witlox M. Evolon ${ }^{\circledR} C R$ microfibre cloth as a tool for varnish removal. CMOP proceedings; 2019.

11. Domingues JAL, Bonelli N, Giorgi R, Fratini E, Gorel F, Baglioni P. Innovative hydrogels based on semi-interpenetrating $\mathrm{p}(\mathrm{HEMA}) / \mathrm{PVP}$ networks for the cleaning of water-sensitive cultural heritage artifacts. Langmuir. 2013;29(8):2746-55. https://doi.org/10.1021/la3048664. 
12. Hermans JJ, Keune K, van Loon A, Corkery RW, ledema PD. Ionomer-like structure in mature oil paint binding media. RSC Adv. 2016;6(96):93363-9. https://doi.org/10.1039/C6RA18267D.

13. Astefanei A, van Bommel M, Corthals GL. Surface acoustic wave nebulisation mass spectrometry for the fast and highly sensitive characterisation of synthetic dyes in textile samples. J Am Soc Mass Spectr. 2017:28(10):2108-16. https://doi.org/10.1007/s13361-017-1716-x.

14. Schilling MR, Heginbotham A, van Keulen H, Szelewski M. Beyond the basics: a systematic approach for comprehensive analysis of organic materials in asian lacquers. Stud Conserv. 2016;61(sup3):3-27. https://doi. org/10.1080/00393630.2016.1230978.
15. Keune K, Boon JJ. Imaging secondary ion mass spectrometry of a paint cross section taken from an early Netherlandish painting by Rogier van der Weyden. Anal Chem. 2004;76(5):1374-85. https://doi.org/10.1021/ ac035201a.

16. Joseph E, Ricci C, Kazarian SG, Mazzeo R, Prati S, loele M. Macro-atr-ft-ir spectroscopic imaging analysis of paint cross-sections. Vibrat Spectrosc. 2010;53(2):274-8. https://doi.org/10.1016/j.vibspec.2010.04.006.

\section{Publisher's Note}

Springer Nature remains neutral with regard to jurisdictional claims in published maps and institutional affiliations.

\section{Submit your manuscript to a SpringerOpen ${ }^{\odot}$ journal and benefit from:}

- Convenient online submission

- Rigorous peer review

- Open access: articles freely available online

- High visibility within the field

- Retaining the copyright to your article

Submit your next manuscript at $\boldsymbol{\nabla}$ springeropen.com 